\title{
Facile Fabrication of 3D Graphene-Silica Hydrogel Composite for Enhanced Removal of Mercury Ions
}

\author{
Jinrong Lu, Xiaonan Wu, Yao Li, Yinghua Liang * and Wenquan Cui * \\ College of Chemical Engineering, Hebei Key Laboratory for Environment Photocatalytic and \\ Electrocatalytic Materials, North China University of Science and Technology, Tangshan 063210, China; \\ lujinrong@ncst.edu.cn (J.L.); uwxnyou@outlook.com (X.W.); liyao139020@gmail.com (Y.L.) \\ * Correspondence: liangyh@ncst.edu.cn (Y.L.); wqcui@ncst.edu.cn (W.C.); Tel.: +86-315-880-5460 (W.C.)
}

Received: 23 January 2019; Accepted: 20 February 2019; Published: 27 February 2019

\begin{abstract}
Adsorption is a highly promising and widely used approach to remove $\mathrm{Hg}$ (II) ions from contaminated water. The key to this technology is exploring the effective adsorbent. The three-dimensional (3D) graphene as reduced graphene oxide hydrogel (rGH)-encapsulated silica gel (SG-PEI/rGH) was prepared by a moderate chemical reduction strategy using ascorbic acid. This composite structure was characterized by FTIR, XRD, and SEM analysis and used as adsorbents for $\mathrm{Hg}$ (II) ions. Its adsorption capacity toward $\mathrm{Hg}$ (II) ions was $266 \mathrm{mg} / \mathrm{g}$ and increased about $32 \%$ compared with the silica gel because of reduced graphene oxide hydrogel (rGH). Mechanism study showed that the high adsorption ability was due to the formation of an $\mathrm{N}-\mathrm{Hg}$ complex with multi-amino groups on the surface of polyethyleneimine-modified silica gel (SG-PEI) and the rapid diffusion of adsorbed ions attributed to the rGH network structure. This composite SG-PEI/rGH would be a promising material for the removal of $\mathrm{Hg}(\mathrm{II})$ ions.
\end{abstract}

Keywords: silica gel; 3D graphene hydrogel; composite; adsorption $\mathrm{Hg}$ (II)

\section{Introduction}

Along with fast industrial development, environmental pollution with heavy metals has increased drastically and become a global issue due to their toxicity [1]. Among the heavy metals, mercury is one of the most poisonous pollutants as it causes a variety of diseases by affecting neurological and renal activities. Released from industrial activities, such as coal combustion, gold mining, battery industry, chloralkali production, and so on, mercury pollutants are introduced into the water as $\mathrm{Hg}$ (II) ions [2,3]. Thus, it is necessary to exploit effective ways to remove $\mathrm{Hg}$ (II) ions from contaminated water.

Several methods, such as chemical precipitation, membrane filtration, ionic exchange, solvent extraction, and adsorption, have been employed for the separation of $\mathrm{Hg}(\mathrm{II})$ ions [4-8]. Among them, adsorption appears to be a highly promising and widely used approach due to high efficiency, low cost, operability, and repeatability [9-11]. The key to this technology is exploring the effective adsorbent. Several kinds of adsorbents have been employed, such as activated carbon [12], chelating resin [13], cellulose [14], metallic oxide [15], and silica gel [16]. Among these adsorbents, silica, gel-based material has attracted more interest in recent decades, because as an inorganic solid matrix, silica gel possesses characteristics such as well-modified surface, chemical stability, high specific areas, and environmental friendliness [17-19]. During the last few years, grafting chelation groups into the silica gel surface had been a major way to develop effective adsorbents based on silica gel. Ligand groups containing nitrogen, oxygen, and sulfur atoms have been employed to improve affinities for $\mathrm{Hg}$ (II) ions [20-23]. In particular, polyamine has been widely used as ligands due to its properties of high density of nitrogen as binding sites for $\mathrm{Hg}$ (II) [16]. However, there are still major challenges to develop silica gel-based adsorbents with high removal efficiency and transmission capability. 
Recently, the development of multifunctional composite materials based on silica gel for the removal of $\mathrm{Hg}$ (II) has attracted considerable attention [24-26]. Graphene and graphene oxide have excellent performance in the adsorption of metal ions because of their large surface area, surface adsorption characteristics, and chemical stability [27-29]. They were combined with silica gel to form composite material as solid-phase extraction sorbents. Liu et al. linked graphene oxide sheets with silica gel via covalent bonds as high-performance adsorbents for solid-phase extraction [30]. Sereshti et al. reported a reduced graphene-modified 3-aminopropyltriethoxysilane $\left(\mathrm{SiO}_{2}-\mathrm{APTES}\right)$ composite used in the solid-phase extraction of $\mathrm{Cr}(\mathrm{VI})$ [31]. Feng et al. prepared reduced graphene oxide-encapsulated silica $\left(\mathrm{SiO}_{2} @ \mathrm{rGO}\right)$ by the hydrothermal reduction strategy. This composite showed excellent adsorption capacity to chlorophenols (CPs) and peptides [32]. As we know, there was no composite composed of graphene and silica gel applied in adsorption of $\mathrm{Hg}$ (II). Herein, three-dimension (3D) graphene as reduced graphene oxide hydrogel (rGH) and polyamines-modified silica gel were integrated to combine their advantages. Firstly, the unique surface adsorption characteristics of graphene and its three-dimensional porous structure provide a fast channel for the movement of $\mathrm{Hg}$ (II) ions. On the other hand, polyamine-modified silica gel can be effectively coordinated with $\mathrm{Hg}$ (II) ions by multi-amino groups. With these considerations, a moderate reduction of GO and polyamine-polyethyleneimine modified silica gel (SG-PEI) mixtures were employed to fabricate 3D-graphene-encapsulated silica gel (SG-PEI/rGH), and the adsorption improvement of silica gel for $\mathrm{Hg}$ (II) was achieved. The composite was characterized by FTIR, SEM, and XRD analysis. The adsorption isotherms and kinetics properties were studied, and the adsorption mechanism was illustrated by XPS.

\section{Materials and Methods}

\subsection{Synthesis of Polyethyleneimine(PEI)-Modified Silica Gel (SG-PEI)}

The synthesis route of SG-PEI was shown in Scheme S1 (see in Supporting Information). First, $3.0 \mathrm{~g}$ of active silica gel was suspended in $100 \mathrm{~mL}$ of dry toluene, and $3 \mathrm{~mL}$ (3-Chloropropyl)trimethoxysilane (CPTS) was added. Then, the mixture was refluxed and stirred in an $\mathrm{N}_{2}$ atmosphere for $12 \mathrm{~h}$. The isolated solid by filtration was treated in a Soxhlet extraction apparatus using toluene and ethanol, respectively, for one day. Then, the solid was dried in vacuum at $55^{\circ} \mathrm{C}$ to obtain SG-Cl.

Next, $1.0 \mathrm{~g}$ of SG-Cl was dissolved in $20 \mathrm{~mL}$ methanol, and $20 \mathrm{~g}$ of polyethyleneimine (PEI) was added. The mixture was stirred under reflux for $10 \mathrm{~h}$. Then, the viscous liquid was washed with water and dried in vacuum at $55^{\circ} \mathrm{C}$ for $48 \mathrm{~h}$ to obtain the solid SG-PEI.

\subsection{Preparation of Amino-Silica Gel and 3D-Graphene Composites (SG-PEI/rGH)}

Graphene oxide was prepared from graphite powder through the modified Hummers method [33]. SG-PEI/rGH was prepared by a simple chemical reduction of SG-PEI/GO by ascorbic acid. Firstly, $200 \mathrm{mg}$ SG-PEI was added into $20 \mathrm{~mL}$ GO suspension with a concentration of $1 \mathrm{mg} / \mathrm{mL}$ under sonication for $1 \mathrm{~h}$. Then, $200 \mathrm{mg}$ ascorbic acid was added into the mixture and was heated to $95^{\circ} \mathrm{C}$ for $1 \mathrm{~h}$ to obtain the composited hydrogel. Then, it was separated from solution and washed with ultrapure water. Before it was used as a sorbent, it was freeze dried under vacuum for $24 \mathrm{~h}$.

\subsection{Adsorption Behaviors Measurement}

\subsubsection{Adsorption Experiment}

First, $20 \mathrm{~mL}$ of mercury ions was placed in solution as perchlorate salt, and $20 \mathrm{mg}$ of the adsorbent was added and stirred at $25^{\circ} \mathrm{C}$ for $24 \mathrm{~h}$. Then, the solution was filtered and the rest of the $\mathrm{Hg}$ (II) 
ions in the solution were tested by atomic absorption spectrophotometer. The adsorption capacity $\left(q\right.$, in $\left.\mathrm{mg} \mathrm{g}^{-1}\right)$ was calculated through the following equation:

$$
q=\frac{\left(C_{0}-C_{e}\right) V}{m}
$$

$C_{0}$ and $C_{e}$ respectively represent the initial and the equilibrium concentrations of $\mathrm{Hg}(\mathrm{II})$ ions $\left(\mathrm{mg} \cdot \mathrm{L}^{-1}\right)$, $V$ represents the volume of the testing solution $(\mathrm{L})$, and $m(\mathrm{~g})$ is the amount of the adsorbent.

The effect of solution $\mathrm{pH}$ on the adsorption was carried out in the $\mathrm{pH}$ range of 1.0-6.0 containing $20 \mathrm{~mL}$ of mercury ions $(400 \mathrm{mg} / \mathrm{L})$.

The effect of the initial $\mathrm{Hg}$ (II) concentration on the adsorption was performed with varying concentrations in the range of $300-420 \mathrm{mg} / \mathrm{L}$ in $\mathrm{pH} 4$. Using the isotherm data and Langmuir and Freundlich models [34], the process of adsorption onto the sorbent was described. The equation of Langmuir and Freundlich adsorption models can be respectively written as:

$$
\begin{aligned}
\frac{c_{e}}{q_{e}} & =\frac{1}{q_{m}} c_{e}+\frac{1}{q_{m} K_{L}} \\
\ln q_{e} & =\frac{1}{n} \ln c_{e}+\ln K_{F}
\end{aligned}
$$

$q_{e}\left(\mathrm{mg} \cdot \mathrm{g}^{-1}\right)$ is adsorption capacity of the equilibrium state, $c_{e}\left(\mathrm{mg} \cdot \mathrm{L}^{-1}\right)$ is the equilibrium concentration of metal ions, $q_{m}$ is the saturated adsorption capacity $\left(\mathrm{mg} \cdot \mathrm{g}^{-1}\right)$, and $K_{L}\left(\mathrm{~L} \cdot \mathrm{mg}^{-1}\right), K_{F}\left(\mathrm{~L} \cdot \mathrm{g}^{-1}\right), n$ are the Langmuir and Freundlich adsorption constants, respectively.

In the fitting isotherms, $\mathrm{R}^{2}$ refers to the Adj.R-Square. It represents the correlation between data and fitting curve.

\subsubsection{Adsorption Kinetics}

To measure the adsorption kinetics, the adsorbents $(20 \mathrm{mg})$ were added to $20 \mathrm{~mL}$ of solution with a mercury ion concentration of $400 \mathrm{mg} / \mathrm{L}$ and stirred at $25^{\circ} \mathrm{C}$. Stirring started at zero time of the adsorption process. Then, the samples were taken at the same time interval, and the adsorption capacity was examined. The kinetic adsorption plots were made according to pseudo-first-order and pseudo-second-order kinetic models. The pseudo-first-order kinetic model was:

$$
\ln \left(q_{e}-q_{t}\right)=\ln q_{e}-k_{1} t
$$

The pseudo-second-order kinetic model was:

$$
\frac{t}{q_{t}}=\frac{1}{k_{2} q_{e}^{2}}+\frac{t}{q_{e}}
$$

$q_{e}$ represents the equilibrium adsorption capacity $\left(\mathrm{mg} \mathrm{g}^{-1}\right), q_{t}$ represents the adsorption capacity at time of $t\left(\mathrm{mg} \cdot \mathrm{g}^{-1}\right)$, and $k_{1}\left(\mathrm{~min}^{-1}\right)$ and $k_{2}\left(\mathrm{~g} \mathrm{mg}^{-1} \cdot \mathrm{min}^{-1}\right)$ respectively represent the rate constants of first-order and second-order adsorption.

In the fitting equations, $\mathrm{R}^{2}$ refers to the Adj.R-Square. It represents the correlation between data and fitting curve.

\section{Results and Discussion}

\subsection{Construction and Characterization of SG-PEI/rGH Composite}

SG-PEI was synthesized from activated silica gel (SG) via intermediate SG-Cl [35]. The modified SGs were characterized using FTIR spectroscopy. As shown in Figure 1a, the new bands appeared at $696 \mathrm{~cm}^{-1}$, corresponding to $\mathrm{C}-\mathrm{Cl}$ vibration in the spectrum of SG-Cl which also retained the 
characteristic peaks at $3440 \mathrm{~cm}^{-1}, 1100 \mathrm{~cm}^{-1}, 974 \mathrm{~cm}^{-1}, 806 \mathrm{~cm}^{-1}$, and $467 \mathrm{~cm}^{-1}$ of silica gel. After reacting with PEI, the band at $696 \mathrm{~cm}^{-1}$ of $\mathrm{C}-\mathrm{Cl}$ band disappeared. Meanwhile the N-H bending vibration band at $1570 \mathrm{~cm}^{-1}$ and the asymmetric and symmetric vibration bands at $2850-2950 \mathrm{~cm}^{-1}$ of $-\mathrm{CH}_{2}$ appeared, indicating the successful modification of SG by PEI [36]. The results of elemental analysis showed the contents of $\mathrm{C}, \mathrm{H}$, and $\mathrm{N}$ in the SG-PEI, also confirming the successful grafting of PEI on the silica gel surface (Table S1).

SG-PEI/rGH was prepared by a simple chemical reduction of SG-PEI/GO by ascorbic acid (Scheme 1). Firstly, SG-PEI and GO were mixed in aqueous solution under sonication, and they were combined well by the hydrogen bonding between $\mathrm{NH}_{2}$ groups of the SG surface and oxygen-obtaining groups such as carboxyl of GO. The hydrogen bonding interaction was proved by FTIR spectroscopy of SG-PEI/rGH in which the N-H and O-H bending vibration peak shifted to a lower wavenumber (Figure 1b). Then, GO was reduced by ascorbic acid to reduced graphene oxide hydrogel (rGH), and the SG-PEI was wrapped inside to form the $\mathrm{NH}_{2}-\mathrm{SG} / \mathrm{rGH}$ composite which was confirmed by FTIR. Compared with $\mathrm{GO}$, the peak at $1730 \mathrm{~cm}^{-1}$ of the oxygen functional group $(\mathrm{C}=\mathrm{O})$ in the spectrum of $\mathrm{NH}_{2}-\mathrm{SG} / \mathrm{rGH}$ disappeared, which confirmed the successful reduction of GO [37]. Meanwhile, the characteristic peaks of SG-PEI suggest the existence of SG-PEI besides rGH in this composite.
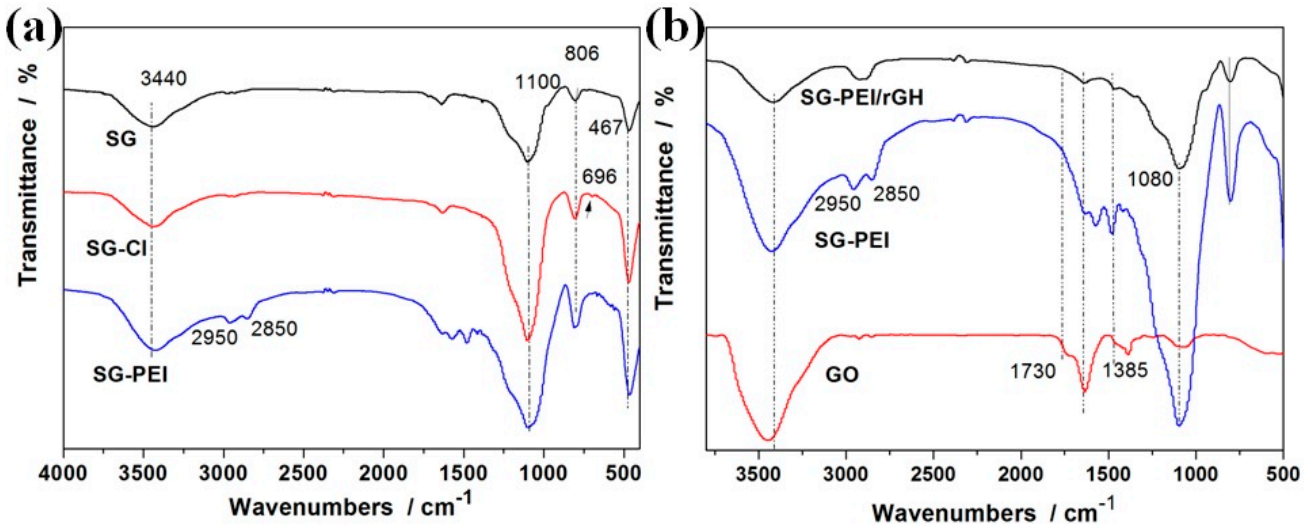

Figure 1. FTIR spectra of (a) SG-PEI and (b) SG-PEI/rGH composite.
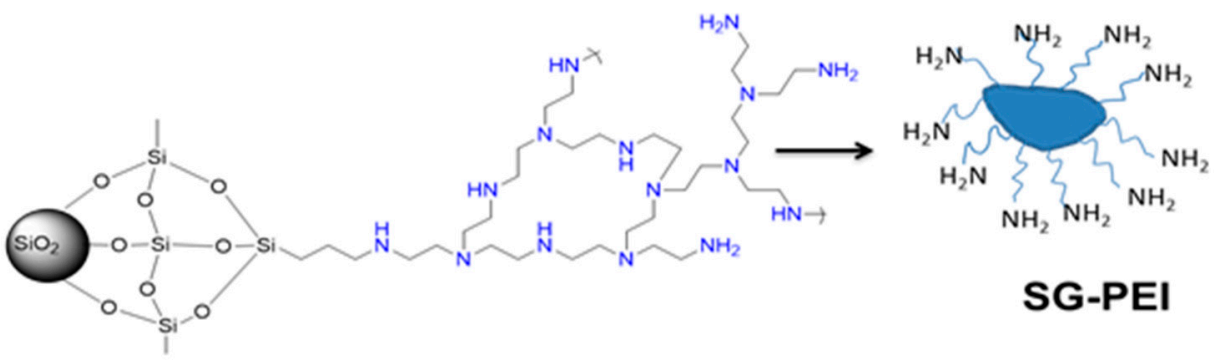

SG-PEI
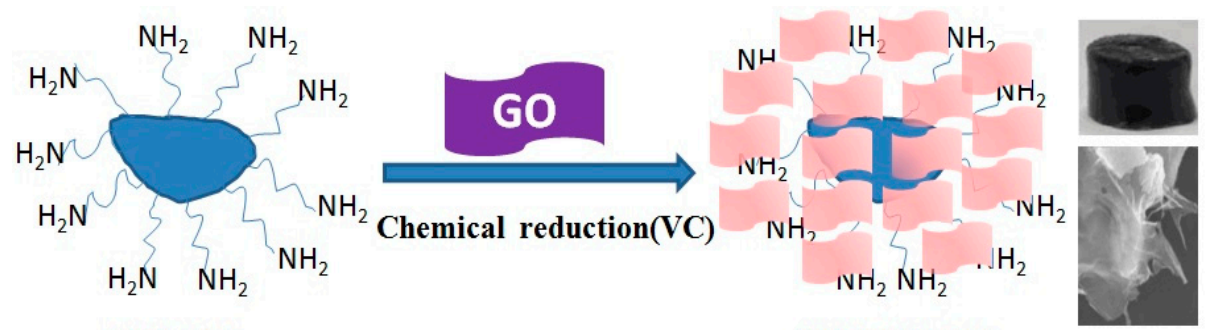

SG-PEI

\section{SG-PEl/rGH}

Scheme 1. The synthesis route of polyamine-polyethyleneimine modified silica gel (SG-PEI)/reduced graphene oxide hydrogel (rGH) composite. 
XRD was also determined to prove the reduction of GO in the composite. In the GO pattern, the diffraction peak at $12.1^{\circ}$ corresponding to the interlayer spacing of $7.6 \AA$ suggested the successful oxidation of graphite (Figure 2) [38]. When GO was reduced to $\mathrm{rGH}$, the broad graphitic diffraction peak at approximately $25.1^{\circ}$ appeared, and the diffraction peak at $12.1^{\circ}$ disappeared. SG-PEI and SG-PEI/rGH showed amorphous structures, and a diffraction peak of rGH was not observed, which indicated that $\mathrm{rGO}$ sheets were disordered and $\mathrm{rGH}$ as a thin layer was dispersed on the $\mathrm{NH}_{2}-\mathrm{SG}$ surface [32]. In addition, there were no extra diffraction peaks in the spectrum, indicating that the third phase did not exist.

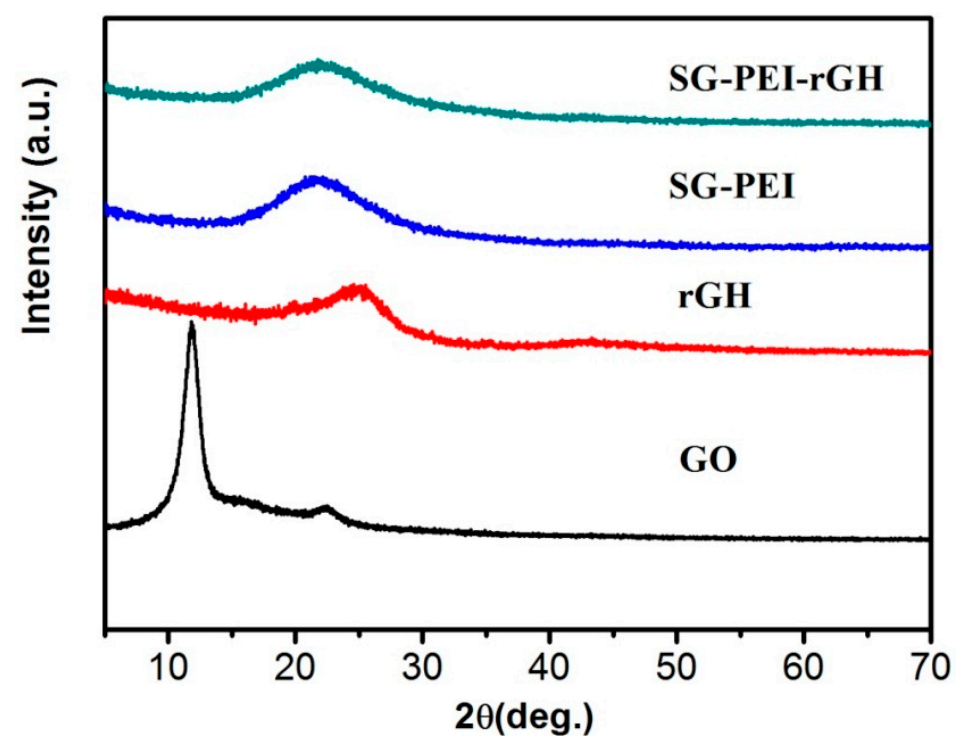

Figure 2. XRD patterns of GO, rGH, SG-PEI, and SG-PEI/rGH

SEM was employed to characterize the morphology of the SG-PEI/rGH composite. It showed modified silica gel particles with an irregular shape (Figure 3a) and a rough surface that was covered with wrinkled gauze structures formed by rGH nanosheets (Figure 3b,c). rGH sheets extended beyond the edge of the SG-PEI, which significantly increased the adsorption site. In addition, rGH sheets also possessed a mesh structure and surface adsorption characteristic which reduce resistance for ion diffusion. The calculated BET (Brunauer-Emmett-Teller) specific surface area of SG-PEI was $182 \mathrm{~m}^{2} / \mathrm{g}$, and when combined with $\mathrm{rGH}$, the specific surface area was increased to $204 \mathrm{~m}^{2} / \mathrm{g}$. Its higher specific surface area can promote the interaction with the adsorbed substance.

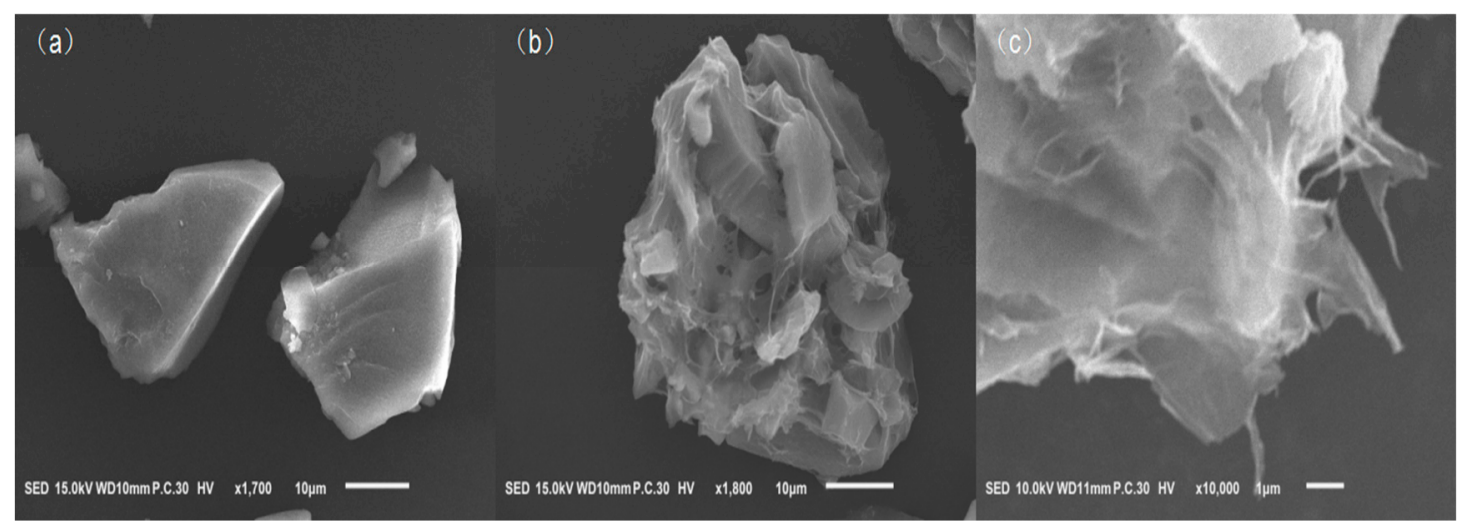

Figure 3. (a) SEM images of SG-PEI (b) SEM images of SG-PEI/rGH (c) the magnified SEM images of SG-PEI/rGH. 


\subsection{The Properties of Adsorption $\mathrm{Hg}(\mathrm{II})$}

\subsubsection{Static Adsorption Capacity and Adsorption Isotherms}

The adsorption of $\mathrm{Hg}$ (II) on the sorbents belongs to surface reaction because of functional groups such as the aminos on the surface of SG-PEI/rGH and because $\mathrm{pH}$ can affect its protonation. Thus, $\mathrm{pH}$ can affect the ability of adsorption of $\mathrm{Hg}$ (II) ions onto the adsorbents. The effect of solution $\mathrm{pH}$ on $\mathrm{Hg}(\mathrm{II})$ adsorption was studied in the range of 1.0-6.0 at $298 \mathrm{~K}$. With the increase in $\mathrm{pH}$ value, the $\mathrm{Hg}$ (II) adsorption capacity of both adsorbents was increased until $\mathrm{pH} 4.0$, and then it began to decrease (Figure 4). At pH 4, the adsorption capacity of SG-PEI/rGH was $266 \mathrm{mg} / \mathrm{g}$, which exceeded most of the adsorbents reported [39], and for SG-PEI, it was $202 \mathrm{mg} / \mathrm{g}$. In the low pH value, protons could compete with $\mathrm{Hg}$ (II) ions with the protonation of amino groups and occupy the active adsorbent sites. In addition, the $\mathrm{Hg}$ (II) adsorption capacity with SG-PEI/rGH was increased compared with that of SG-PEI. With the increased $\mathrm{pH}$, the amino groups were free, and the competitive adsorption between $\mathrm{H}^{+}$and $\mathrm{Hg}^{2+}$ was more weakened than that at low $\mathrm{pH}$. As the $\mathrm{pH}$ continued to increase, the forms of $\mathrm{Hg}^{2+}$ changed to $\mathrm{Hg}(\mathrm{OH})^{+}$or $\mathrm{Hg}(\mathrm{OH})_{2}$ when the mercury concentration was above $120 \mathrm{mg} / \mathrm{L}$ [40], causing the reduced adsorption capacity.

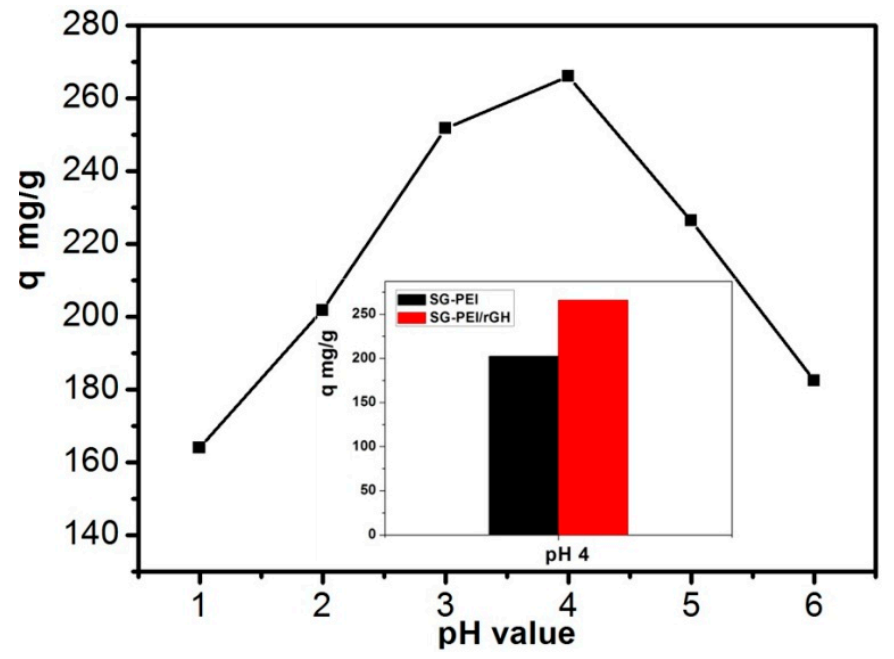

Figure 4. The effect of $\mathrm{pH}$ on adsorption capacity.

The effect of initial $\mathrm{Hg}$ (II) ion concentration on the adsorption at $298 \mathrm{~K}$ was examined, and the results were shown in Figure 5a. It could be observed that the adsorption amount of $\mathrm{Hg}$ (II) increased as the initial $\mathrm{Hg}$ (II) concentrations gradually reached a platform, which was due to the saturation adsorption on the active sites of the SG-PEI/rGH. Figure $5 b$ showed the adsorption isotherms of SG-PEI/rGH at different temperatures, such as $25^{\circ} \mathrm{C}, 35^{\circ} \mathrm{C}$, and $45^{\circ} \mathrm{C}$. It was observed that as the temperature increased, the adsorption amount of $\mathrm{Hg}^{2+}$ also increased. The isotherm data were fitted according to the Langmuir and Freundlich equations. The fitted plots were shown in Figure 6 and the corresponding constants were in Table 1. It was revealed that the Langmuir equation well fitted the adsorption isotherm indicated by the more significant correlation than that of Freundlich equation (The coefficients and standard errors are listed in Table S2). In addition, the adsorption capacity of $q_{m}$ obtained by the Langmuir theory was $278 \mathrm{mg} \cdot \mathrm{g}^{-1}$, which was close to the experimental value. This result suggested a monolayer adsorption of $\mathrm{Hg}$ (II) on SG-PEI/rGH. 
(a)

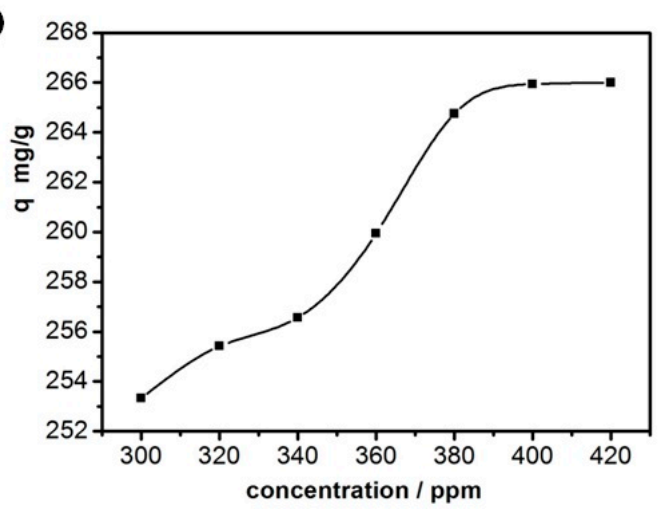

(b)

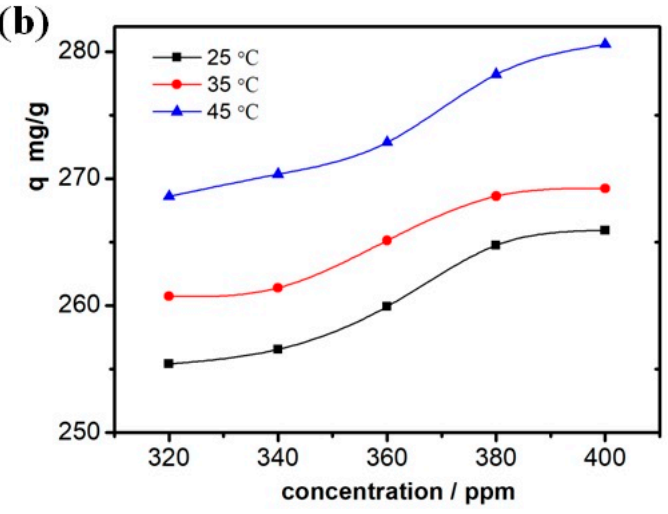

Figure 5. (a) The effect of $\mathrm{Hg}^{2+}$ initial concentration on adsorption quantity (b) The adsorption isotherm of $\mathrm{Hg}^{2+}$ at different temperatures.

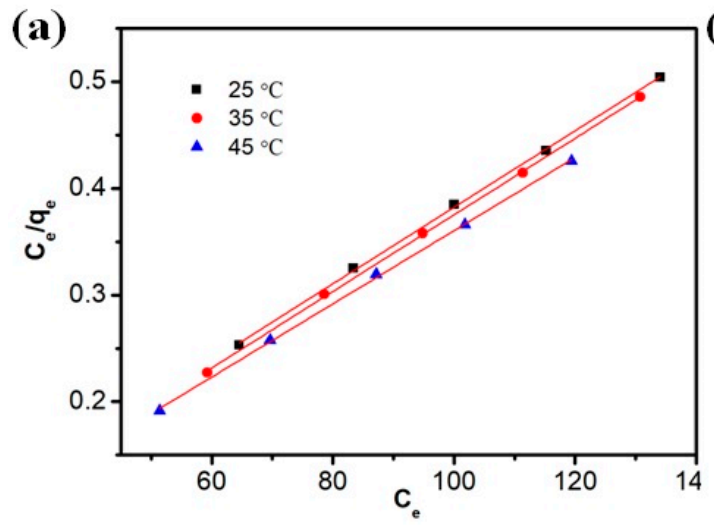

(b)

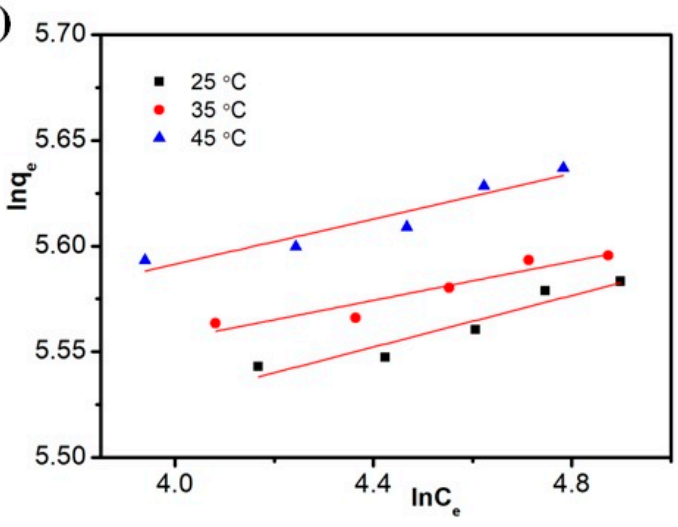

Figure 6. (a) Langmuir and (b) Freundlich isotherm for the sorption of $\mathrm{Hg}^{2+}$ onto SG-PEI/rGH at different temperatures.

Table 1. Isotherm parameter of Langmuir and Freundlich for the adsorption of $\mathrm{Hg}^{2+}$ obtained by using linear method at different temperatures.

\begin{tabular}{|c|c|c|c|c|c|c|c|}
\hline \multirow{2}{*}{ Torbent } & \multirow{2}{*}{$\mathrm{T}(\mathrm{K})$} & \multicolumn{3}{|c|}{ Langmuir } & \multicolumn{3}{|c|}{ Freundlich } \\
\hline & & $K_{L}\left(\mathrm{~L} \cdot \mathrm{mg}^{-1}\right)$ & $q_{m}\left(\mathrm{mg} \cdot \mathrm{g}^{-1}\right)$ & $R_{L}^{2}$ & $K_{F}\left(\mathrm{~L} \cdot \mathrm{g}^{-1}\right)$ & $n$ & $R_{F}^{2}$ \\
\hline \multirow{3}{*}{ SG-PEI-rGH } & 298.15 & 0.1537 & 278.5515 & 0.99929 & 197.1569 & 16.4015 & 0.8872 \\
\hline & 308.15 & 0.2209 & 278.5515 & 0.99963 & 215.2564 & 21.7250 & 0.8780 \\
\hline & 318.15 & 0.1993 & 291.5452 & 0.99924 & 216.3332 & 18.6428 & 0.8753 \\
\hline
\end{tabular}

To identify the thermodynamic properties of this adsorption process, thermodynamic constants such as Gibbs free energy $(\Delta G)$, enthalpy change $(\Delta H)$, and entropy change $(\Delta S)$ were determined (Figure S1) and shown in Table 2. $\Delta \mathrm{G}$ was negative for the all-adsorption process at different temperatures, and the absolute values were increased as temperature was increased. It suggested that this adsorption was spontaneous and thermodynamically favorable [41]. The $\Delta \mathrm{H}$ was positive, which indicated that this adsorption was endothermic, and the increased temperature was good for the adsorption process [23]. The thermodynamic results were consistent with experimental phenomena.

Table 2. Thermodynamic parameters of $\mathrm{Hg}^{2+}$ adsorption on SG-PEI-rGH.

\begin{tabular}{|c|c|c|c|c|}
\hline $\begin{array}{c}\mathrm{T} \\
(\mathrm{K})\end{array}$ & $\ln K$ & $\begin{array}{c}\Delta \mathrm{G} \\
\left(\mathrm{KJ} \cdot \mathrm{mol}^{-1}\right)\end{array}$ & $\begin{array}{c}\Delta \mathrm{H} \\
\left(\mathrm{KJ} \mathrm{mol}^{-1}\right)\end{array}$ & $\begin{array}{c}\Delta S \\
\left(\mathrm{~J} \mathrm{~mol}^{-1} \mathrm{~K}^{-1}\right)\end{array}$ \\
\hline 298.15 & 1.9695 & -4.8820 & & \\
\hline 308.15 & 2.0577 & -5.2718 & 9.1121 & 46.8698 \\
\hline 318.15 & 2.2014 & -5.8229 & & \\
\hline
\end{tabular}




\subsubsection{Adsorption Kinetics}

The adsorption kinetics of $\mathrm{Hg}$ (II) by SG-PEI and SG-PEI/rGH were shown in Figure 7. For the two adsorbents, the adsorption rates of $\mathrm{Hg}$ (II) were both rapidly increased in the early stage of the process, and the main adsorption amount was accomplished in $2 \mathrm{~h}$. Then, the adsorption rate changed slowly and reached to equilibrium after $10 \mathrm{~h}$. In contrast, for SG-PEI, about $90 \%$ of total adsorption amount was accomplished within $2 \mathrm{~h}$, and for SG-PEI/rGH, within $2 \mathrm{~h}$, only about $70 \%$ of total adsorption amount was accomplished. Compared with SG-PEI, the increase in adsorption capacity for SG-PEI/rGH was mainly due to the increase in adsorption in the later adsorption stage after $2 \mathrm{~h}$. This may be due to the rGH network structure loaded on the SG-PEI surface, which was favorable for the rapid diffusion of adsorbed ions. Therefore, at a later stage, the adsorption capacity would continue to increase.

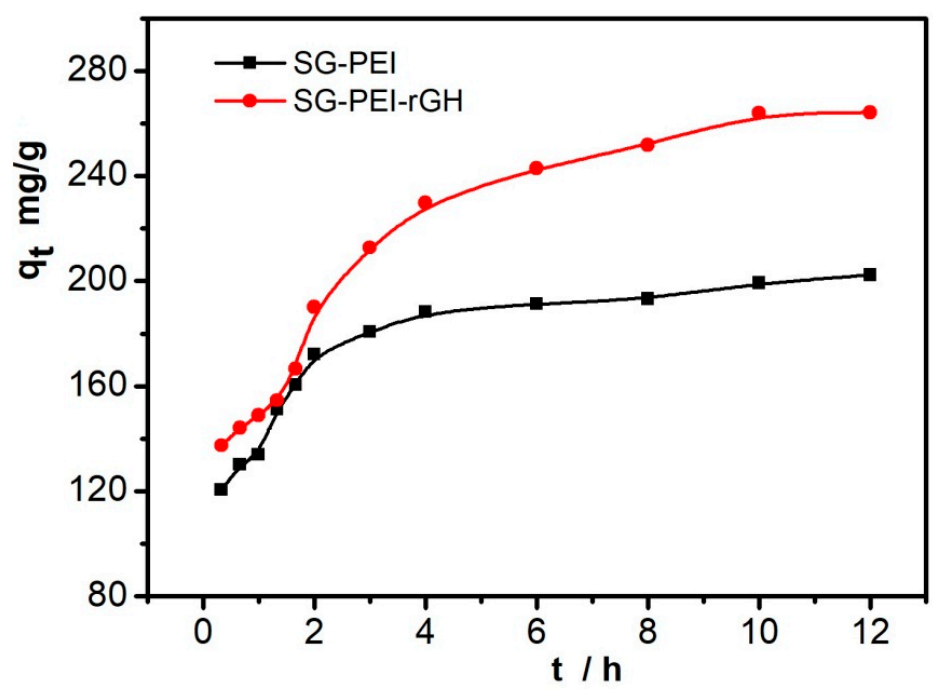

Figure 7. Kinetic sorption plot of $\mathrm{Hg}^{2+}$ on SG-PEI and SG-PEI/rGH.

Pseudo-first-order and pseudo-second-order equations were employed respectively to fit the adsorption kinetic plots (Figure 8), and the corresponding kinetic constants for the two models are listed in Table 3 (Coefficients and standard errors of fitting equations are listed in Table S3). It showed that the correlation coefficients $\left(\mathrm{R}^{2}\right)$ of the pseudo-second-order kinetic model for the two adsorbents were both higher than that of pseudo-first-order model, which means that these adsorption kinetics could be well described by the pseudo-second-order model and that this adsorption process was mainly controlled by chemisorption [42].
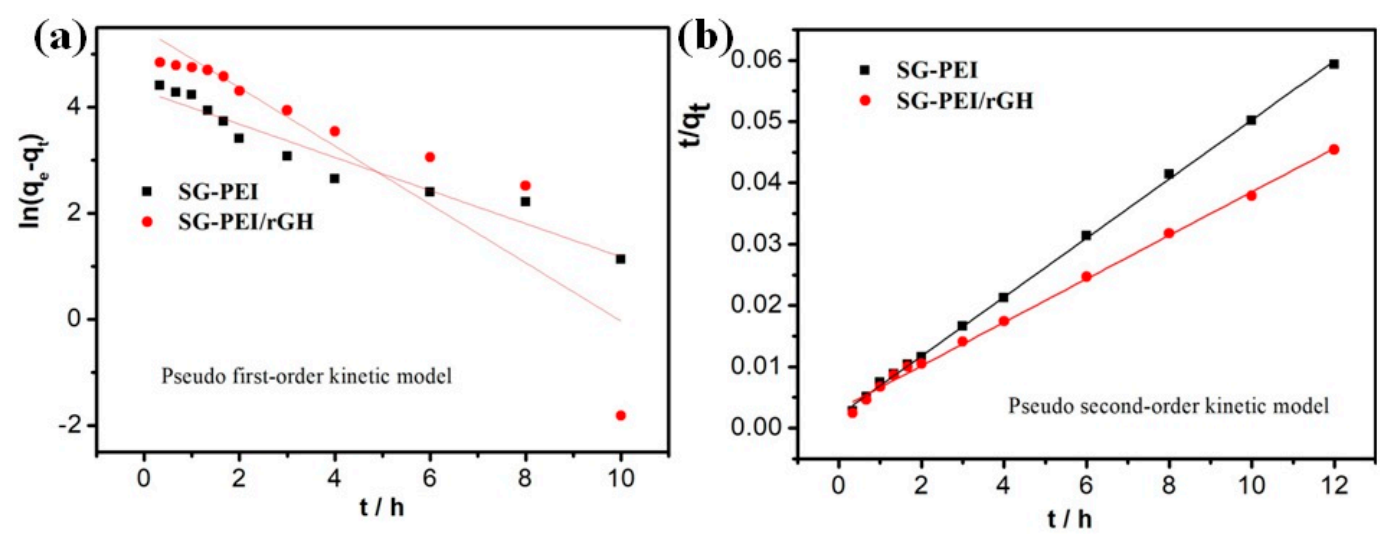

Figure 8. (a) Pseudo first-order kinetic model and (b) pseudo second-order kinetic model of SG-PEI and SG-PEI/rGH for $\mathrm{Hg}^{2+}$. 
Table 3. Kinetic parameter of the adsorption of $\mathrm{Hg}^{2+}$ onto SG-PEI and SG-PEI-rGH adsorbents.

\begin{tabular}{|c|c|c|c|c|c|c|c|c|}
\hline \multirow[b]{2}{*}{ Sorbent } & \multirow[b]{2}{*}{$\mathrm{T}(\mathrm{K})$} & \multirow{2}{*}{$\begin{array}{c}q_{e}(\exp ) \\
\left(\mathrm{mg} \cdot \mathrm{g}^{-1}\right)\end{array}$} & \multicolumn{3}{|c|}{ Pseudo-First-Order Kinetics } & \multicolumn{3}{|c|}{ Pseudo-Second-Order Kinetics } \\
\hline & & & $\begin{array}{c}k_{1} \\
\left(\min ^{-1}\right)\end{array}$ & $\begin{array}{c}q_{e}(\mathrm{cal}) \\
\left(\mathrm{mg} \cdot \mathrm{g}^{-1}\right)\end{array}$ & $\mathbf{R}_{\mathbf{1}}{ }^{2}$ & $\frac{k_{2}}{\left(\mathrm{~g} \cdot \mathrm{mg}^{-1} \cdot \min ^{-1}\right)}$ & $\begin{array}{c}q_{e}(\mathrm{cal}) \\
\left(\mathrm{mg} \cdot \mathrm{g}^{-1}\right)\end{array}$ & $\mathbf{R}_{2}{ }^{2}$ \\
\hline SG-PEI & 308.15 & 202.2859 & 0.3122 & 73.7359 & 0.9347 & 0.0109 & 207.4689 & 0.9993 \\
\hline SG-PEI-rGH & 308.15 & 264.1632 & 0.5495 & 235.4244 & 0.8093 & 0.0041 & 281.6901 & 0.9966 \\
\hline
\end{tabular}

\subsubsection{The Effect of Coexisted Ions}

The coexisted cations in waste water would occupy adsorption sites of $\mathrm{Hg}$ (II) ions, hindering the adsorption process [43]. Therefore, common cations such as calcium, potassium, and sodium ions as nitrate salts were mixed with $\mathrm{Hg}$ (II) ions to examine their effects on adsorption of $\mathrm{Hg}(\mathrm{II})$ at the concentration range of $1-15 \mathrm{mmol} \mathrm{L}^{-1}$ for each cation. The adsorption results are listed in Figure 9, and it was observed that the salts had a slight inhibition to adsorption for $\mathrm{Hg}$ (II) ions, and when the concentration of $\mathrm{Na}^{+}, \mathrm{K}^{+}, \mathrm{Ca}^{2+}$, and $\mathrm{NO}_{3}{ }^{-}$in solution was $15 \mathrm{mmol} / \mathrm{L}, 15 \mathrm{mmol} / \mathrm{L}, 15 \mathrm{mmol} / \mathrm{L}$, and $60 \mathrm{mmol} / \mathrm{L}$ respectively, the removal rate can still reach over $85 \%$ without interference ions. Thus, the effect was relatively slight, indicating that SG-PEI/rGH as an adsorbent of $\mathrm{Hg}$ (II) showed excellent anti-interference to these ions in solution.

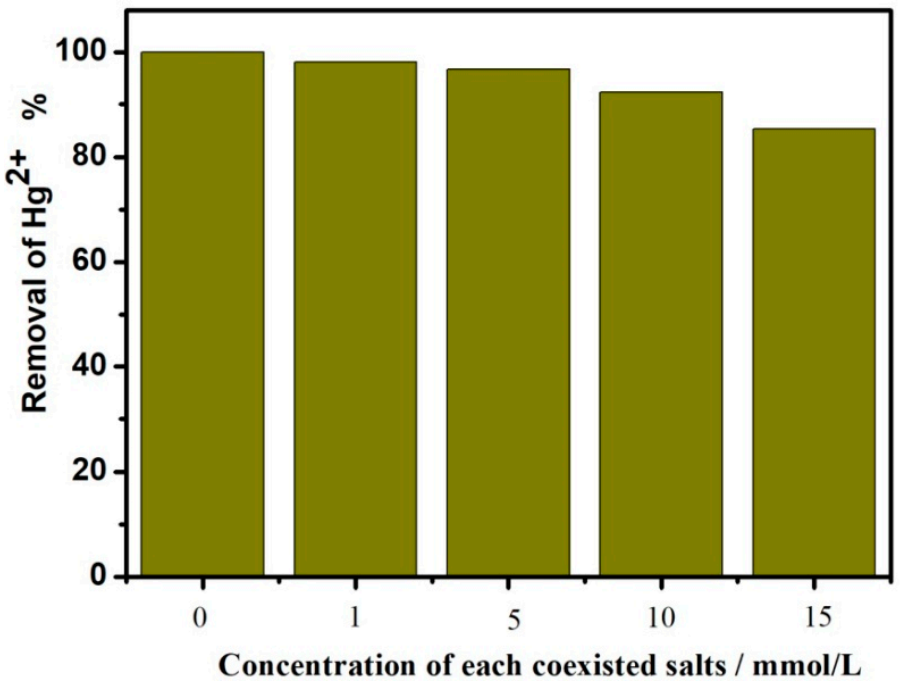

Figure 9. The effect of coexisting ion concentration on adsorption.

\subsubsection{Desorption and Adsorption Cycles}

The reusability of a sorbent is very important for its application, so the adsorption-desorption cycles were investigated (Figure 10). Dilute $\mathrm{HCl}$ solution (1 M) containing thiourea (2\%) and cysteine $(0.1 \mathrm{M})$ were chosen as the eluent to desorb loaded $\mathrm{Hg}$ (II) ions on SG-PEI/rGH. Then, to remove residual eluent, SG-PEI/rGH was washed with deionized water and employed for $\mathrm{Hg}$ (II) adsorption in the next cycles. It was observed that the adsorption efficiency was still about $75 \%$ after four cycles, which suggested that the SG-PEI/rGH showed good recycle capacity for $\mathrm{Hg}$ (II) adsorption. 


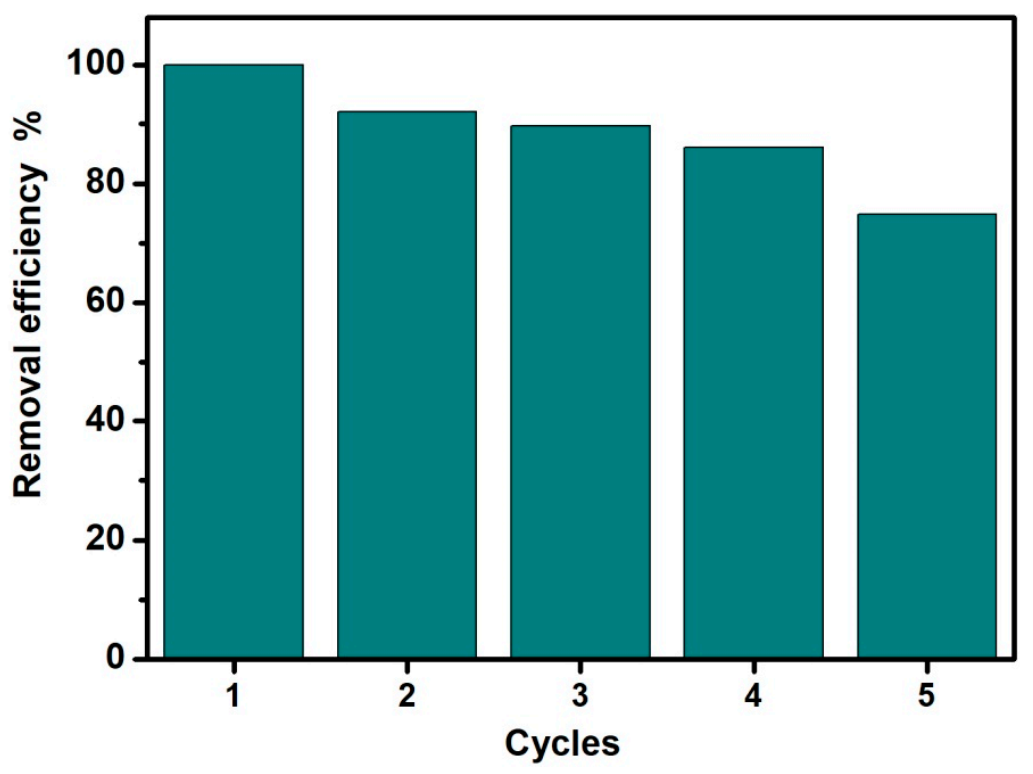

Figure 10. Adsorption-desorption cycle of SG-PEI/rGH for $\mathrm{Hg}^{2+}$.

3.2.5. Mechanism of Adsorption $\mathrm{Hg}$ (II) Ions

The X-ray photoelectron spectra (XPS) of SG-PEI/rGH were tested before and after adsorption $\mathrm{Hg}$ (II) ions to identify the interaction mechanism, and the results were shown in Figure 11. It was observed that after interaction with $\mathrm{Hg}(\mathrm{II})$ ions, the peaks of $\mathrm{Hg} 4 \mathrm{~d}$ at $360 \mathrm{eV}$ and $379 \mathrm{eV}$ appeared, indicating that $\mathrm{Hg}(\mathrm{II})$ ions were loaded on the sorbent SG-PEI/rGH [44]. The spectra of N1s were resolved into two component peaks at $400.05 \mathrm{eV}$ and $401.90 \mathrm{eV}$ assigned to the $\mathrm{N}$ atoms in $-\mathrm{NH}^{-\mathrm{NH}_{2}}$ and $-\mathrm{NR}_{2}$ of PEI. After interaction with $\mathrm{Hg}(\mathrm{II})$ ions, they were shifted to $400.47 \mathrm{eV}$ and $402.45 \mathrm{eV}$, respectively, which indicated the formation of $\mathrm{N}-\mathrm{Hg}$ coordination [45]. Therefore, it was speculated that this adsorption process based on chemical adsorption was due to the strong coordination interaction of the $\mathrm{N}$ atom with $\mathrm{Hg}$ (II) (Figure 12).

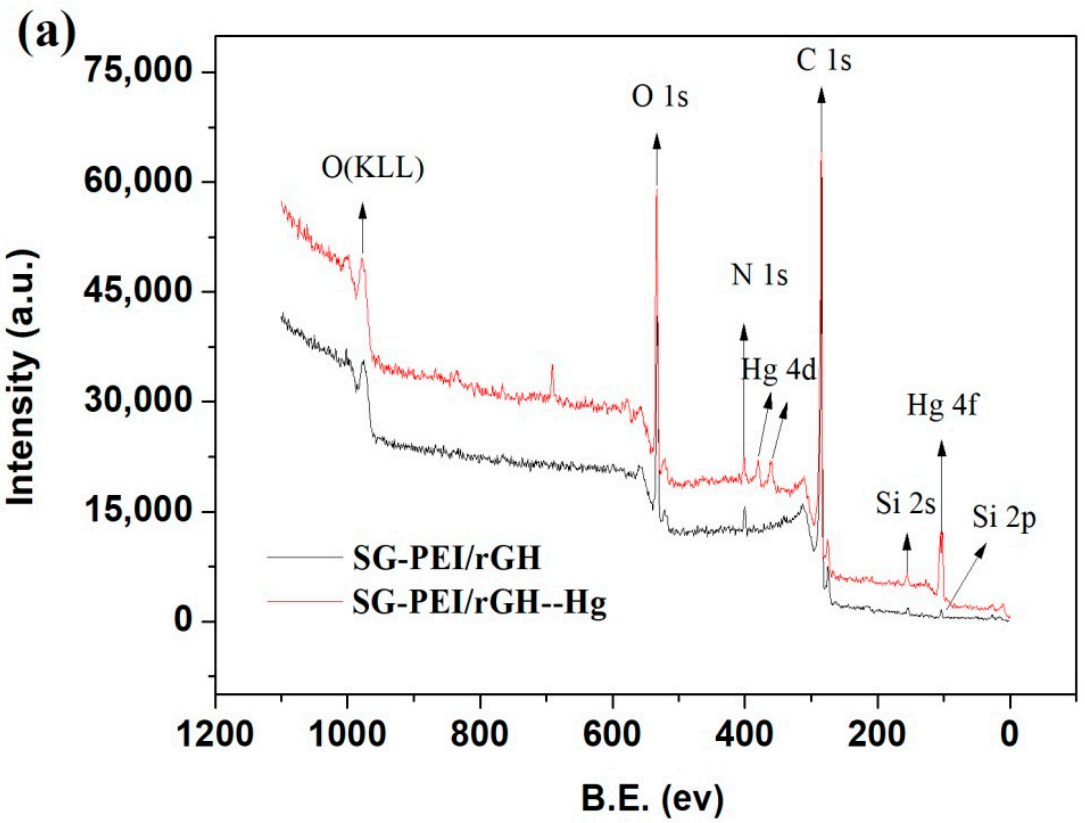

Figure 11. Cont. 

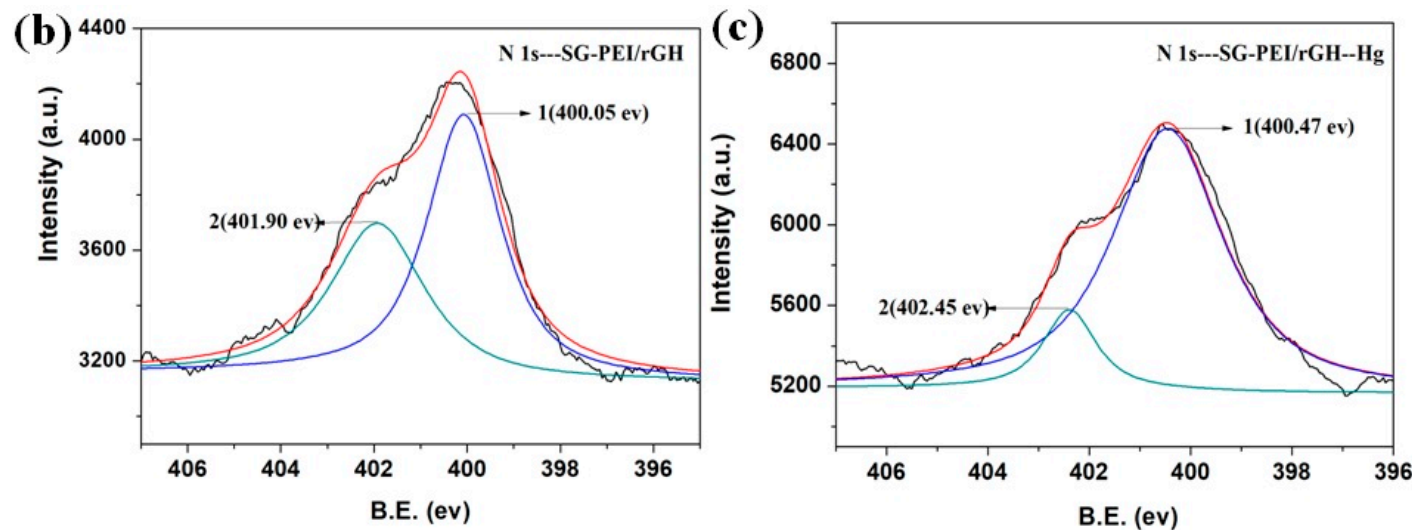

Figure 11. (a) XPS wide scan and (b,c) N1s spectrum of SG-PEI/rGH and SG-PEI/rGH-Hg.

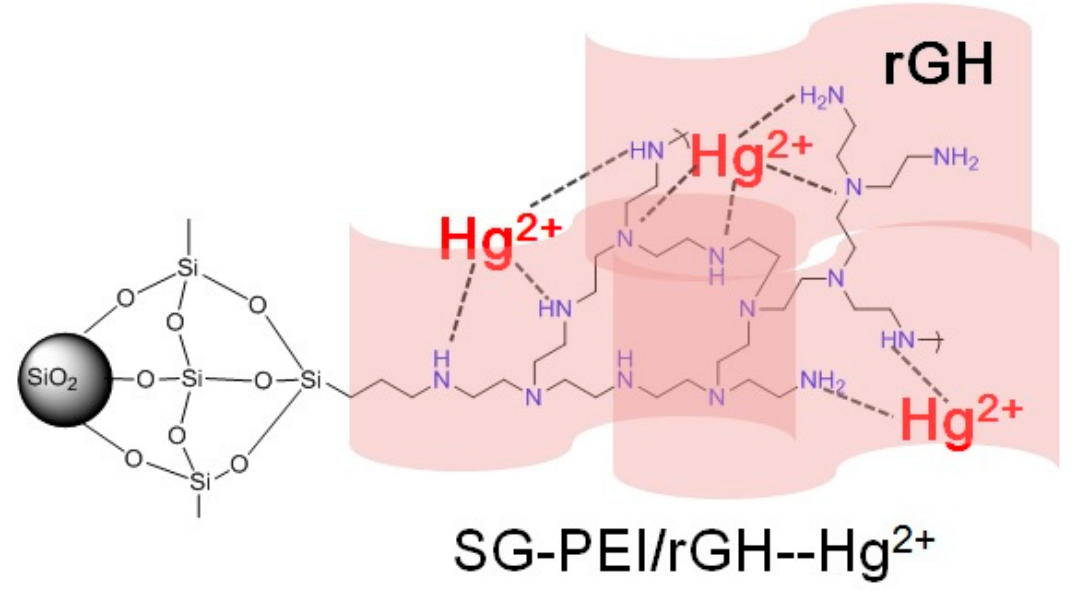

Figure 12. Mechanism for adsorption of $\mathrm{Hg}(\mathrm{II})$ on SG-PEI/rGH.

\section{Conclusions}

In summary, 3D, reduced graphene oxide hydrogel (rGH)-modified SG-PEI was prepared and employed in the adsorption $\mathrm{Hg}$ (II) ions. Compared with SG-PEI, it showed an improvement in adsorption capacity towards $\mathrm{Hg}(\mathrm{II})$ ions and operable recovery based on the presence of $\mathrm{rGH}$. A kinetics and mechanism study showed that the high adsorption capacity was attributed to the formation of an $\mathrm{N}-\mathrm{Hg}$ complex with multi-amino groups on the SG-PEI surface and the rapid diffusion of adsorbed ions because of the rGH network structure. Overall, SG-PEI/rGH would be a promising material for the removal of $\mathrm{Hg}$ (II) ions. Additionally, this work provides a new strategy for preparing 3D rGH-encapsulated silica, and it is expected that the composite material may also be extended to applications in other environmental purification processes.

Supplementary Materials: The following are available online at http://www.mdpi.com/2079-4991/9/3/314/s1, Scheme S1: The synthesis route of SG-PEI from SG, Table S1: Elemental analysis of surface functionalized silica gel, Table S2: Coefficients and standard errors of fitting Langmuir and Freundlich isotherm, Table S3: Coefficients and standard errors of fitting Pseudo-first-order and pseudo-second-order equations, Figure S1: (a): $\ln K_{d}$ vs. $C_{e}$ plot and (b) lnK vs. 1/T plot for the adsorption of $\mathrm{Hg}^{2+}$ on SG-PEI-rGH.

Author Contributions: Conceptualization, J.L., X.W., Y.L. (Yinghua Liang) and W.C.; methodology, J.L., X.W., Y.L. (Yao Li) and W.C.; validation, J.L., Y.L. (Yinghua Liang) and W.C.; formal analysis, X.W., Y.L. (Yao Li) and J.L.; writing-original draft preparation, J.L., Y.L. (Yinghua Liang) and W.C.; writing-review and editing, J.L., X.W. and W.C.; visualization, J.L. and X.W.; supervision, Y.L. (Yinghua Liang); project administration, W.C.; funding acquisition, J.L., Y.L. (Yinghua Liang) and W.C.

Funding: This research was funded by Natural Science Foundation of Hebei Province (No. B2016209139), the support program for one hundred excellent talents of innovation in Hebei provincial universities (III) (No. SLRC2017049), and the National Natural Science Foundation of China (No. 51372068). 
Conflicts of Interest: The authors declare no conflict of interest.

\section{References}

1. Niu, Y.; Qu, R.; Sun, C.; Wang, C.; Chen, H.; Ji, C.; Zhang, Y.; Shao, X.; Bu, F. Adsorption of Pb(II) from aqueous solution by silica-gel supported hyperbranched polyamidoamine dendrimers. J. Hazard. Mater. 2013, 244, 276-286. [CrossRef] [PubMed]

2. Rumayor, M.; Diaz-Somoano, M.; Lopez-Anton, M.A.; Martinez-Tarazona, M.R. Application of thermal desorption for the identification of mercury species in solids derived from coal utilization. Chemosphere 2015, 119, 459-465. [CrossRef] [PubMed]

3. Wang, J.X.; Feng, X.B.; Anderson, C.W.N.; Xing, Y.; Shang, L.H. Remediation of mercury contaminated sites-A review. J. Hazard. Mater. 2012, 221-222, 1-18. [CrossRef] [PubMed]

4. Rezvani-Boroujeni, A.; Javanbakht, M.; Karimi, M.; Shahrjerdi, C.; Akbari-adergani, B. Immoblization of thiol-functionalized nanosilica on the surface of poly (ether sulfone) membranes for the removal of heavy-metal ions from industrial wastewater samples. Ind. Eng. Chem. Res. 2014, 54, 502-513. [CrossRef]

5. Boukhelkhal, A.; Benkortbi, O.; Hamadeche, M.; Hanini, S.; Amrane, A. Removal of amoxicillin antibiotic from aqueous solution using an anionic surfactant. Water Air Soil Pollut. 2015, 226, 1-12. [CrossRef]

6. Werber, J.R.; Osuji, C.O.; Elimelech, M. Materials for next-generation desalination and water purification membranes. Nat. Rev. Mater. 2016, 1, 16018. [CrossRef]

7. Nayab, S.; Farrukh, A.; Oluz, Z.; Tuncel, E.L.; Tariq, S.R.; Rahman, H.U.; Kirchhoff, K.; Duran, H.; Yameen, B. Design and fabrication of branched polyamine functionalized mesoporous silica: An efficient absorbent for water remediation. ACS Appl. Mater. Interfaces 2014, 6, 4408-4417. [CrossRef] [PubMed]

8. Zhou, Q.; Duan, Y.; Chen, M.; Liu, M.; Lu, P. Studies on mercury adsorption species and equilibrium, on activated carbon surface. Energy Fuels 2017, 31, 14211-14218. [CrossRef]

9. Wang, T.; Wu, J.; Zhang, Y.; Liu, J.; Sui, Z.; Zhang, H.; Chen, W.Y.; Norris, P.; Pan, W.P. Increasing the chlorine active sites in the micropores of biochar for improved mercury adsorption. Fuel 2018, 229, 60-67. [CrossRef]

10. Yang, Y.; Liu, J.; Zhang, B.; Liu, F. Mechanistic studies of mercury adsorption and oxidation by oxygen over spinel-type $\mathrm{MnFe}_{2} \mathrm{O}_{4}$. J. Hazard. Mater. 2017, 321, 154-161. [CrossRef] [PubMed]

11. Zhou, C.; Zhu, H.; Wang, Q.; Wang, J.; Cheng, J.; Guo, Y.; Zhou, X.; Bai, R. Adsorption of mercury(II) with an $\mathrm{Fe}_{3} \mathrm{O}_{4}$ magnetic polypyrrole-graphene oxide nanocomposite. RSC Adv. 2017, 7, 18466-18479. [CrossRef]

12. Faulconer, E.K.; Mazyck, D.W. Influence of activated carbon surface oxygen functionality on elemental mercury adsorption from aqueous solution. J. Environ. Chem. Eng. 2017, 5, 2879-2885. [CrossRef]

13. Qu, R.J.; Sun, C.M.; Zhang, Y.; Chen, J.; Wang, C.H.; Ji, C.N.; Liu, X.G. Syntheses, characterization, and $\mathrm{Hg}(\mathrm{II})$ adsorption properties of porous cross-linked polystyrene modified with 2-aminopyridine via a sulfoxide/sulfone-containing spacer arm. J. Chem. Eng. Data 2010, 55, 4343-4351. [CrossRef]

14. Bansal, M.; Ram, B.; Chauhan, G.S.; Kaushik, A. L-Cysteine functionalized bagasse cellulose nanofibers for mercury(II) ions adsorption. Int. J. Biol. Macromol. 2018, 112, 728-736. [CrossRef] [PubMed]

15. Yao, T.; Duan, Y.; Zhu, C.; Zhou, Q.; Xu, J.; Liu, M.; Wei, H. Investigation of mercury adsorption and cyclic mercury retention over $\mathrm{MnOx} / \gamma-\mathrm{Al}_{2} \mathrm{O}_{3}$ sorbent. Chemosphere 2018, 202, 358-365. [CrossRef] [PubMed]

16. Niu, Y.; Qu, R.; Chen, H.; Mu, L.; Liu, X.; Wang, T.; Zhang, Y.; Sun, C. Synthesis of silica gel supported salicylaldehyde modified PAMAM dendrimers for the effective removal of $\mathrm{Hg}(\mathrm{II})$ from aqueous solution. J. Hazard. Mater. 2014, 278, 267-278. [CrossRef] [PubMed]

17. Mohammed, R.H.; Mesalhy, O.; Elsayed, M.; Hou, L.S.; Su, M.; Chow, L.C. Physical properties and adsorption kinetics of silica-gel/water for adsorption chillers. Appl. Therm. Eng. 2018, 137, 368-376. [CrossRef]

18. Vodianitskaia, P.J.; Soares, J.J.; Melo, H.; Gurgel, J.M. Experimental chiller with silica gel: Adsorption kinetics analysis and performance evaluation. Energy Convers. Manag. 2017, 132, 172-179. [CrossRef]

19. Zhang, Y.; Qu, R.; Sun, C.; Ji, C.; Chen, H.; Yin, P. Improved synthesis of silica-gel-based dendrimer-like highly branched polymer as the Au(III) adsorbents. Chem. Eng. J. 2015, 270, 110-121. [CrossRef]

20. Fu, K.L.; Yao, M.Y.; Qin, C.G.; Cheng, C.W.; Lin, Y.; Cai, M.; Yang, S.; Nie, J.P. Study on the removal of oxidized mercury $\left(\mathrm{Hg}^{2+}\right)$ from flue gas by thiol chelating resin. Fuel Process. Technol. 2016, 148, $28-34$. [CrossRef] 
21. Choi, J.M.; Jeong, D.; Cho, E.; Jun, B.H.; Park, S.; Yu, J.H.; Tahir, M.N.; Jung, S. Chemically functionalized silica gel with alkynyl terminated monolayers as an efficient new material for removal of mercury ions from water. J. Ind. Eng. Chem. 2016, 35, 376-382. [CrossRef]

22. Fan, H.T.; Liu, J.X.; Yao, H.Z.; Zhang, G.; Yan, F.; Li, W.X. Ionic Imprinted Silica-Supported Hybrid Sorbent with an Anchored Chelating Schiff Base for Selective Removal of Cadmium(II) Ions from Aqueous Media. Ind. Eng. Chem. Res. 2014, 53, 369-378. [CrossRef]

23. Arshadi, M.; Faraji, A.R.; Amiri, M.J. Modification of aluminum-silicate nanoparticles by melamine-based dendrimer L-cysteine methyl esters for adsorptive characteristic of $\mathrm{Hg}(\mathrm{II})$ ions from the synthetic and Persian Gulf. Water Chem. Eng. J. 2015, 266, 345-355. [CrossRef]

24. Niu, Y.; Yang, J.; Qu, R.; Gao, Y.; Du, N.; Chen, H.; Sun, C.; Wang, W. Synthesis of Silica-Gel-Supported Sulfur-Capped PAMAM Dendrimers for Efficient $\mathrm{Hg}(\mathrm{II})$ Adsorption: Experimental and DFT Study. Ind. Eng. Chem. Res. 2016, 55, 3679-3688. [CrossRef]

25. Ganzagh, M.A.A.; Yousefpour, M.; Taherian, Z. The removal of mercury (II) from water by Ag supported on nanomesoporous silica. J. Chem. Biol. 2016, 9, 1-16. [CrossRef] [PubMed]

26. Wang, Z.; Yin, P.; Qu, R.; Xu, Q. Heterogeneous synthesis of chelating resin organophosphonic acid-functionalized silica gel and its adsorption property of heavy metal ions from fuel ethanol solutions. J. Appl. Polym. Sci. 2012, 126, 544-551. [CrossRef]

27. Luo, X.; Zhang, F.; Ji, S.; Yang, B.; Liang, X. Graphene nanoplatelets as a highly efficient solid-phase extraction sorbent for determination of phthalate esters in aqueous solution. Talanta 2014, 120, 71-75. [CrossRef] [PubMed]

28. Huang, B.; Liu, Y.; Li, B.; Liu, S.; Zeng, G.; Zeng, Z.; Wang, X.; Ning, Q.; Zheng, B.; Yang, C. Effect of Cu(II) ions on the enhancement of tetracycline adsorption by $\mathrm{Fe}_{3} \mathrm{O}_{4} @ \mathrm{SiO}_{2}-\mathrm{Chitosan} /$ graphene oxide nanocomposite. Carbohydr. Polym. 2017, 157, 576-585. [CrossRef] [PubMed]

29. Peng, W.; Li, H.; Liu, Y.; Song, S. A review on heavy metal ions adsorption from water by graphene oxide and its composites. J. Mol. Liq. 2017, 230, 496-504. [CrossRef]

30. Liu, Q.; Shi, J.; Sun, J.; Wang, T.; Zeng, L.; Jiang, G. Graphene and graphene oxide sheets supported on silica as versatile and high-performance adsorbents for solid-phase extraction. Angew. Chem. 2011, 123, 6035-6039. [CrossRef]

31. Sereshti, H.F.; Vasheghani, M.; Baghdadi, M. Trace determination of chromium(VI) in environmental water samples using innovative thermally reduced graphene (TRG) modified $\mathrm{SiO}_{2}$ adsorbent for solid phase extraction and UV-vis spectrophotometry. Talanta 2016, 146, 662-669. [CrossRef] [PubMed]

32. Luo, Y.B.; Zhu, G.T.; Li, X.S.; Yuan, B.F.; Feng, Y.Q. Facile fabrication of reduced graphene oxide-encapsulated silica: A sorbent for solid-phase extraction. J. Chromatogr. A 2013, 1299, 10-17. [CrossRef] [PubMed]

33. Li, Y.; Cui, W.; Liu, L.; Zong, R.; Yao, W.; Liang, Y.; Zhu, Y. Removal of Cr(VI) by 3D TiOn-graphene hydrogel via adsorption enriched with photocatalytic reduction. Appl. Catal. B Environ. 2016, 199, 412-423. [CrossRef]

34. Nandi, B.; Goswami, A.; Purkait, M. Removal of cationic dyes from aqueous solutions by kaolin: Kinetic and equilibrium studies. Appl. Clay Sci. 2009, 42, 583-590. [CrossRef]

35. Lei, J.; Abu-Daabes, M.; Pinto, N.G. Thermally robust chelating adsorbents for the capture of gaseous mercury: Fixed-bed behavior. Chem. Eng. Sci. 2009, 64, 486-491.

36. Li, J.; Chen, Q.; Yang, L. The synthesis of dendrimer based on the dielectric barrier discharge plasma grafting amino group film. Surf. Coat. Technol. 2010, 205, S257-S260. [CrossRef]

37. Tiwari, J.N.; Mahesh, K.; Le, N.H.; Kemp, K.C.; Timilsina, R.; Tiwari, R.N.; Kim, K.S. Reduced graphene oxide-based hydrogels for the efficient capture of dye pollutants from aqueous solutions. Carbon 2013, 56, 173-182. [CrossRef]

38. Rao, C.N.R.; Biswas, K.K.; Subrahmanyam, S.; Govindaraj, A. Graphene, the new nanocarbon. J. Mater. Chem. 2009, 19, 2457-2469. [CrossRef]

39. Liu, M.; Tao, Z.; Wang, H.; Zhao, F.; Sun, Q. Study on the adsorption of Hg(II) by one-pot synthesis of amino-functionalized graphene oxide decorated with a $\mathrm{Fe}_{3} \mathrm{O}_{4}$ microsphere nanocomposite. RSC Adv. 2016, 6, 84573-84586. [CrossRef]

40. Zhang, F.S.; Nriagu, J.O.; Itoh, H. Mercury removal from water using activated carbons derived from organic sewage sludge. Water Res. 2005, 39, 389-395. [CrossRef] [PubMed]

41. Li, Y.H.; Di, Z.; Ding, J.; Wu, D.; Luan, Z.; Zhu, Y. Adsorption thermodynamic, kinetic and desorption studies of $\mathrm{Pb}^{2+}$ on carbon nanotubes. Water Res. 2005, 39, 605-609. [CrossRef] [PubMed] 
42. Lin, Y.F.; Chen, H.W.; Chien, P.S.; Chiouc, C.S.; Liu, C.C. Application of bifunctional magnetic adsorbent to adsorb metal cations and anionic dyes in aqueous solution. J. Hazard. Mater. 2011, 185, 1124-1130. [CrossRef] [PubMed]

43. Puanngam, M.; Unob, F. Preparation and use of chemically modified MCM-41 and silica gel as selective adsorbents for $\mathrm{Hg}(\mathrm{II})$ ions. J. Hazard. Mater. 2008, 154, 578-587. [CrossRef] [PubMed]

44. Dong, J.; Xu, Z.; Wang, F. Engineering and characterization of mesoporous silica-coated magnetic particles for mercury removal from industrial effluents. Appl. Surf. Sci. 2008, 254, 3522-3530. [CrossRef]

45. Bai, L.; Hu, H.; Fu, W.; Wan, J.; Cheng, X.; Zhuge, L.; Xiong, L.; Chen, Q. Synthesis of a novel silica-supported dithiocarbamate adsorbent and its properties for the removal of heavy metal ions. J. Hazard. Mater. 2011, 195, 261-275. [CrossRef] [PubMed]

(C) 2019 by the authors. Licensee MDPI, Basel, Switzerland. This article is an open access article distributed under the terms and conditions of the Creative Commons Attribution (CC BY) license (http:/ / creativecommons.org/licenses/by/4.0/). 